\title{
Structural Breaks and Unit Root in Macroeconomic Time Series: Evidence from Nigeria
}

\author{
Omorogbe Joseph Asemota ${ }^{1}$ and Adejumo Oluwasegun Agbailu ${ }^{2}$ \\ ${ }^{1}$ Department of Research and Training, Department of Statistics, National Institute \\ for Legislative Studies, University of Abuja, Abuja. \\ ${ }^{2}$ Department of Statistics, University of Abuja. \\ *Corresponding Author: asemotaomos@yahoo.com
}

Received: $20^{\text {th }}$ December 2016/ Revised: $9^{\text {th }}$ February 2017 / Accepted: $18^{\text {th }}$ August 2017

CIAppStat-SL2017

\section{ABSTRACT}

The discourse on the properties of macroeconomic time series has received a considerable interest in recent literature. This is because the presence of unit in a realization of a stochastic process implies that shocks to the time series have a persistent effect with policy implications. Hence, this paper investigates the unit root properties of ten Nigerian macroeconomic time series using quarterly data from 1981-2015. For comparison, first we apply the conventional augmented DickeyFuller unit root test to examine the null of a unit root in the ten macroeconomic series, and we proceed to examine the unit root properties using the Lagrange Multiplier (LM) endogenous unit root tests that account for the presence of onebreak and two-break as proposed by Lee and Strazicich (2003, 2013). On employing the augmented Dickey-Fuller test that does not account for structural breaks, our empirical results indicate that the unit root null hypothesis cannot be rejected for nine of the ten series considered in the study. However, on utilizing the Lagrange Multiplier (LM) endogenous one and two structural breaks test, we reject the unit root null in favour of the one and two-break stationary alternative for six of the ten series (60\% rejection) considered in our study. These results imply that unit root tests that do not account sufficiently for the presence of structural breaks lead to misleading inference. These findings have important implications for the macroeconomic policy-making, modeling and forecasting of the Nigerian economy. We therefore, recommend that structural breaks should be taken into account in the econometric analysis of Nigerian macroeconomic variables.

Keywords: macroeconomic time series, recession, structural breaks, stationarity, unit roots.JEL Classification: C20, C22, C51, C52, C53

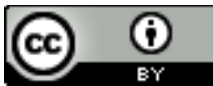

IASSL 


\section{Introduction}

\subsection{Introduction to the Research Problem}

Studies on macroeconomic time series properties have received a considerable interest in recent literature. One of the most topical debates among economists is whether macroeconomic time series can be characterised as a random walk (unit root) or trend-stationary. The conventional views of the business cycle theories suggest that output fluctuations (shocks) are temporary deviations from their longrun stable path. Hence, the impact of shocks on output growth will eventually fade and output will return to its trend rate of growth. This implies that output series such as GNP is characterised as trend stationary. This traditional view of economists is, however, contrary to what empirical findings suggested. The findings challenge the traditional view in treating economic time series as temporary fluctuations around a deterministic trend function as opposed to the permanent changes reflected in the trend. In their seminal contribution to the unit root properties of macroeconomic time series, Nelson and Plosser (1982) revealed that the GDP series of USA followed a random walk. They argued that most of the changes in the GDP are permanent, indicating that there is no tendency for output growth to revert to its underlying trend following a shock. Hence, shocks will persist in every future period and GDP is said to follow a random walk.

Perron (1989) demonstrated that Nelson and Plosser's strong evidence in support of the unit root hypothesis is due to the failure to account for structural changes in the data. Perron (1989) incorporated an exogenous structural break for the 1929 crash in the conventional unit root test (augmented Dickey-Fuller test). On accounting for structural break, the unit root hypothesis is rejected for eleven out of the fourteen series analysed by Nelson and Plosser (1982). However, during the early 1990s, Banerjee et al.(1992), Christiano (1992) and Zivot and Andrews (1992) opined that choosing the structural break(s) exogenously could lead to over-rejection of the unit root hypothesis. To address this problem, they proposed the one endogenous structural break test.

Lumsdaine and Papell (1997) modified the endogenous break methodology to account for two endogenous breaks in the trend equation. They found more evidence against the unit root hypothesis than Zivot and Andrews (1992), but less than Perron (1989). Specifically, Lumsdaine and Papell (1997) rejected the unit root hypothesis at the five per cent level for seven out of thirteen series considered by Nelson and Plosser (1982) and at the ten per cent level for additional two series. A limitation of the augmented Dickey-Fuller (ADF)-type endogenous break unit root tests, such as the Zivot and Andrews (1992) and Lumsdaine and Papell (1997) tests, is that the critical values are derived while assuming no break(s) under the null. Nunes et al.(1997) and Lee and Strazicich (2003) show that this assumption leads to size 
distortions in the presence of a unit root with one or two breaks. Hence, when utilizing the Zivot and Andrews (1992) and Lumsdaine and Papell (1997) tests, spurious rejections may occur. To circumvent these spurious rejections, Lee and Strazicich (2013) propose a one break Lagrange Multiplier (LM) unit root test as an alternative to the Zivot and Andrews (1992) test, while Lee and Strazicich (2003) developed a two-break LM unit root test as a substitute for the Lumsdaine and Papell (1997) test. In contrast to the ADF test, the LM unit root test incorporates breaks under the null and alternative hypotheses. Tatoglu (2009) investigated the stationarity of real effective exchange rates using panel unit root tests with structural breaks, and he found evidence in support of structural breaks. Chaudhuri and $\mathrm{Wu}$ (2003) investigated whether stock prices of seventeen emerging markets can be characterised as random walk (unit root) or mean reversion processes. They implemented a test that accounts for structural breaks in the underlying series and noted that failure to account for structural breaks lead to erroneous conclusion that these indices are characterized by random walk.

Folawewo (2012) applied the unit root with structural break test to test for the presence of hysteresis in Nigerian unemployment rate. Waheed et al. (2006) examined the unit root with structural break for the Pakistani macroeconomic time series. On employing the conventional unit root test without structural breaks, all the 11 macroeconomic variables of the Pakistani economy were non-stationary. However, on employing the Zivot-Andrews unit root test with structural break, they found evidence of stationarity in two of the macroeconomic series. In addition, structural break was detected in ten of the eleven series considered in their study. Narayan and Smyth (2005) analysed the random walk hypothesis of stock prices in OECD countries using unit root tests that account for one and two structural breaks in the trend function. They concluded that structural break in stock prices has had a detrimental effect on movements in stock prices in the G7 countries. In addition, Luísa et al. (2006) pointed out that standard unit root tests provided mixed evidence on the stochastic behaviour of the Brazilian gross domestic product series. Furthermore, Bjørnland (2010) investigated the dynamic properties of several macroeconomic variables in Norway using different unit root tests and measures of persistence. He found that on accounting for a structural break in the trend alternative, the unit root hypothesis for unemployment, government consumption, investment and real wage was rejected.

\subsection{Research Problem}

Howbeit, most of the previous studies on Nigerian macroeconomic time series [Adaramola (2012), Osamwonyi and Osagie (2012), Tamunonimim (2013) etc.] have never employed the two structural breaks LM test in their empirical analysis. 
This study is being proposed against this backdrop. With this, we hope to fill an existing lacuna in the empirical literature. To the best of our knowledge, this study is the first attempt to utilize the Langrage multiplier one-break and two-break unit tests to model the Nigerian macroeconomic time series. It contributes to the empirical literature by providing evidence of structural break(s) in Nigerian major economic time series. In addition, the conventional ADF test is used as a benchmark in this analysis. The rest of the paper is structured as follows: Section 2 explains the econometric methodology. Section 3 presents the data and the empirical results and the last section concludes.

\section{Econometric Methodology}

This section briefly discussed the methodology of this empirical study.

\subsection{The augmented Dickey-Fuller (ADF) Test}

It has become a tradition in the statistical analysis of macroeconomic time series, that the unit root hypothesis is first tested for each of the variables to ascertain its order of integration. The augmented Dickey-Fuller (Dickey and Fuller, 1979, 1981) test is the most commonly used test for ascertaining the presence of unit root. In the case of trending data, it is based on the following regression:

$$
\Delta y_{t}=\alpha+\emptyset y_{t-1}+\beta^{*} t+\sum_{i=1}^{k} \theta_{i} \Delta y_{t-i}+\varepsilon_{t}
$$

This involves a regression of $\Delta y_{t}$ on $y_{t-1}, \Delta y_{t-1}, \Delta y_{t-2}, \ldots, \Delta y_{t-p}$ as well as an intercept $\alpha$ and time trend $\beta^{*} t, \mathrm{t}=1,2, \ldots \mathrm{T}$ and $\varepsilon_{t}$ a pure white noise disturbance with variance of $\sigma^{2} . \Delta y_{t-i}$ is the lagged first differences to correct for serial autocorrelation in the errors. The optimal lag length $(k)$ is selected using $t$-sig approach as proposed by Hall (1994) with $k$-max $=4$. $\mathrm{Ng}$ and Perron (1995) used a simulation study to show that the 't-sig' approach is preferable to the information based criteria.

\subsection{Lee and Strazicich Structural Break Model}

The Langrange Multiplier (LM) based structural break test was developed by Lee and Strazicich (2003) to circumvent the spurious rejection problems associated with the Zivot and Andrews (1992) and Perron (1989) endogenous break test. Consider the data generating process (DGP) as follows:

$$
y_{t}=\delta^{\prime} Z_{t}+e_{t}, \quad e_{t}=\beta e_{t-1}+\varepsilon_{t},
$$


where $Z_{t}$ is a vector of exogenous variables and $\varepsilon_{t} \sim$ IID $N\left(0, \sigma^{2}\right)$. Two structural breaks can be considered as follows: Model A allows for two shifts in level and is described by $Z_{t}=\left[1, \mathrm{t}, D_{1 t}, D_{2 t}\right]^{\prime}$, where $D_{j t}=1$ for $\mathrm{t} \geq T_{B j}+1, j=1,2$, and 0 otherwise. $T_{B j}$ denotes the time period when a break occurs. Model $\mathrm{C}$ includes two changes in level and trend and is described by $Z_{t}=\left[1, \mathrm{t}, D_{1 t}, D_{2 t}, D T_{1 t}, D T_{2 t}\right]^{\prime}$, where $D T_{j t}=\mathrm{t}-T_{B j}$ for $\mathrm{t} \geq T_{B j}+1, j=1,2$, and 0 otherwise. Note that the DGP includes breaks under the null $(\beta=1)$ and alternative $(\beta<1)$ hypothesis in a consistent manner. For instance, in model A (a similar argument can be applied to model C), depending on the value of $\beta$, we have:

Null

$$
y_{t}=\mu_{0}+d_{1} B_{1 t}+d_{2} B_{2 t}+y_{t-1}+v_{1 t}
$$

Alternative

$$
y_{t}=\mu_{1}+\gamma t+d_{1} D_{1 t}+d_{2} D_{2 t}+v_{2 t}
$$

where $v_{1 t}$ and $v_{2 t}$ are stationary error terms; $B_{j t}=1$ for $t=T_{B j}+1, \mathrm{j}=1,2$ and 0 otherwise; and $\mathrm{d}=\left(d_{1}, d_{2}\right)$ and $\gamma$ is the trend parameter. In model C, $D_{j t}$ terms are added to (3) and $D T_{j t}$ terms to (4), respectively. Note that the null model (3) includes dummy variables $B_{j t}$. Perron $(1989, \mathrm{p} .1393)$ showed that including $B_{j t}$ is necessary to ensure that the asymptotic distribution of the test statistic is invariant to the size of breaks $(d)$ under the null. The two-break LM unit root test is implemented using the regression as follows:

$$
\Delta y_{t}=d^{\prime} \Delta Z_{t}+\phi \tilde{S}_{t-i}+\sum_{i=1}^{k} \lambda_{i} \Delta \tilde{S}_{t-j}+\varepsilon_{t}
$$

where $\tilde{S}_{t}$ is a de-trended series such that $\tilde{S}_{t}=y_{t}-\tilde{\psi}_{x}-Z_{t} \tilde{\delta}, t=2, \ldots, T . \tilde{\delta}$ is a vector of coefficients in the regression of $\Delta y_{t}$ on $\Delta Z_{t}$ and $\tilde{\psi}_{x}=y_{1}-Z_{1} \tilde{\delta}$, where $y_{1}$ and $Z_{1}$ are the first observations of $y_{t}$ and $Z_{t}$, respectively, and $\Delta$ is the difference operator, $\varepsilon_{t}$ is the contemporaneous error term and distributed with zero mean and finite variance, $\Delta \tilde{S}_{t-j}, j=1, \ldots, k$, terms are added to correct for serial correlation. Analogous to the two-break equivalent of Perron (1989) Model C, with two breaks in level and trend, $Z_{t}$ is defined by $\left[1, \mathrm{t}, D_{1 t}, D_{2 t}, D T_{1 t}, D T_{2 t}\right]$ to allow for a constant term, linear time trend, and two structural breaks in level and trend. The unit root null hypothesis is given as $\phi=0$, and the LM test statistics are given by:

$$
\begin{aligned}
& \widetilde{\rho}=T \tilde{\phi}, \\
& \tilde{\tau}=\mathrm{t} \text {-statistic for the null hypothesis } \phi=0 .
\end{aligned}
$$

To endogenously determine the break points $\left(T_{B j}\right)$, the minimum LM unit root test uses a grid search as follows:

$$
\begin{aligned}
& L M_{\rho}=\inf _{\lambda} \tilde{\rho}(\tilde{\lambda}) \\
& L M_{\tau}=\inf _{\lambda} \tilde{\tau}(\lambda)
\end{aligned}
$$


where $=T_{b} / T$, and $\mathrm{T}$ is the sample size. Vougas (2003) indicated that in the application of LM test, the studentized version $(\tilde{\tau})$ takes, into account, the variability of the estimated coefficients and is more powerful than the coefficient $\operatorname{test}(\tilde{\rho})$. The breakpoints are determined to be where the test statistic is minimized. As expected in endogenous break test, a trimming region of $(0.15 \mathrm{~T}, 0.85 \mathrm{~T})$ is used to eliminate endpoints. Critical values are tabulated in Lee and Strazicich (2003).

\section{Data and Empirical Results}

\subsection{Data}

The methodology described in section 2 is applied to 10 Nigerian macroeconomic time series data. The Government Final Expenditure, Gross Domestic Product, All Share Index, Exports of Goods and Services, Imports of Goods and Services, Compensation of Employees (Wages), Crude Oil Price, Inflation Rate (CPI), Exchange Rate and Money and Quasi Money (M2). Data are quarterly and are extracted from the Central Bank of Nigeria (CBN) Statistical Database. With the exception of the government final expenditure, crude oil price, inflation rate, official exchange rate and money supply (M2) which are analyzed in levels, the other series are converted to logarithm for variance stabilization. The EViews and RATS statistical packages are used in carrying out all the analysis in this study. Table 1 presents the macro variables and their codes as used in the analysis.

Table 1: Variable description

\begin{tabular}{|ll|c|}
\hline \multicolumn{1}{|c|}{ Variables } & Code \\
\hline 1. & Government Final Expenditure & GOFE \\
\hline 2. & Gross Domestic Product & LGDP \\
\hline 3. & All Share Index & LASHI \\
\hline 4. & Exports of Goods and Services & LEXPO \\
\hline 5. & Imports of Goods and Services & LIMPO \\
\hline 6. & Compensation of Employees (Wages) & LWAGE \\
\hline 7. & Crude Oil Price & CROP \\
\hline 8. & Inflation Rate & INFL \\
\hline 9. & Official Exchange Rate (Naira to Dollar) & EXCH \\
\hline 10. Money and Quasi Money (M2) & M2 \\
\hline
\end{tabular}

Note: L denotes natural logarithm. Variables are in local currency (Naira)

\subsection{Unit Root Test without Structural Break}

The ADF test without structural break is first employed to analyze the unit root properties of the series. The results from the ADF test with a linear time trend are reported in Table 2. Using the ADF test, the unit root cannot be rejected for 9 of the 
10 series. However, the unit root can be rejected for imports of goods and services at 10 per cent level of significance. From the analysis of the 10 Nigerian macroeconomic time series, we found little evidence against the unit root hypothesis. Howbeit, according to Perron (1989), the ADF test could lead to misleading inferences if potential structural breaks are ignored.

Table 2: ADF test without structural break

\begin{tabular}{|c|c|c|c|}
\hline Macro-variables & $\widehat{\boldsymbol{k}}$ & Test statistic & Inference \\
\hline GOFE & 4 & -1.43486 & Unit Root \\
\hline LGDP & 0 & -1.42051 & Unit Root \\
\hline LEXPO & 1 & -2.71713 & Unit Root \\
\hline LIMPO & 0 & $-3.33309 *$ & Stationary \\
\hline LASHI & 4 & -1.16024 & Unit Root \\
\hline LWAGE & 0 & -2.34995 & Unit Root \\
\hline CPI & 4 & -0.38763 & Unit Root \\
\hline EXCH & 0 & -2.06246 & Unit Root \\
\hline CROP & 2 & -2.27129 & Unit Root \\
\hline M2 & 2 & 2.67948 & Unit Root \\
\hline denote statistical significance at $10 \%$ & & \\
\hline
\end{tabular}

* denote statistical significance at $10 \%$

Note: Linear trend is included in the estimation of the model. The critical values for the above ADF test are -4.03 and, -3.45 and -3.15 for at 1,5 and 10 percent respectively. $\hat{\mathrm{k}}$ is the AIC lag term is used to select the optimal lag, to make the residuals white noise.

Perron (1989) demonstrated that if there is a structural break, the power to reject a unit root decreases when the stationary break alternative is true and structural break(s) is ignored. Hence, this finding is consistent with the unit root literature and is due to the low power of the ADF when structural breaks are present in the series.

\subsection{Unit Root Test with One Structural Break}

The results Lee and Strazicich unit root test with one endogenous structural break are presented in Table 3. Using the LM one-break endogenous test, the unit root hypothesis can be rejected for gross domestic products at $1 \%$ level of significant and for government final expenditure at 5\% level significant. The empirical results reported in Table 3 indicates that $20 \%$ of the 10 Nigerian macroeconomic series reject the unit root hypothesis at conventional (5\%) level of significant and $80 \%$ of the 10 Nigeria macroeconomic series could not reject the unit root hypothesis. 
Table 3: One endogenous structural break Lee-Strazicich unit root test

\begin{tabular}{|c|c|c|c|c|c|}
\hline $\begin{array}{l}\text { Variabl } \\
\text { es }\end{array}$ & $\widehat{\boldsymbol{k}}$ & $\begin{array}{l}\text { Break } \\
\text { Date }\end{array}$ & $\begin{array}{l}\text { Test } \\
\text { Statistic }\end{array}$ & $\begin{array}{l}\text { Break Point } \\
(\lambda)\end{array}$ & Inference \\
\hline GOFE & 4 & 2008:03 & $-4.5451^{* *}$ & 0.8 & $\begin{array}{l}\text { Stationary with one- } \\
\text { break }\end{array}$ \\
\hline LGDP & 3 & 2009:03 & $-5.6392 * * *$ & 0.8 & $\begin{array}{l}\text { Stationary with one- } \\
\text { break }\end{array}$ \\
\hline LEXPO & 1 & 2009:04 & -3.8236 & 0.9 & Unit Root \\
\hline LIMPO & 0 & 1986:03 & -4.1956 & 0.2 & Unit Root \\
\hline LASHI & 4 & 2004:03 & -2.9145 & 0.7 & Unit Root \\
\hline LWAGE & 0 & 2004:02 & -3.0869 & 0.7 & Unit Root \\
\hline CPI & 4 & 2006:01 & -2.9975 & 0.5 & Unit Root \\
\hline $\mathrm{EXCH}$ & 1 & 1999:02 & -2.8088 & 0.5 & Unit Root \\
\hline CROP & 2 & 2004:02 & -3.8490 & 0.7 & Unit Root \\
\hline M2 & 4 & 2003:03 & -3.9320 & 0.7 & Unit Root \\
\hline
\end{tabular}

$* * *, * *$ and $*$ denote statistical significance at $1 \%, 5 \%$ and $10 \%$ respectively.

Note: $\hat{\mathrm{k}}$ is the AIC lag term is used to select the optimal lag, to make the residuals white noise. denotes the estimated break points.

Table 4: Lee and Strazicich Critical Values for One Structural Break Test

\begin{tabular}{|c|c|c|c|}
\hline Break points & \multicolumn{3}{|c|}{ Critical values } \\
\hline$=\left(\mathrm{T}_{\mathrm{B}} / \mathrm{T}\right)$ & $1 \%$ & $5 \%$ & $10 \%$ \\
$=(0.1)$ & -5.11 & -4.5 & -4.21 \\
\hline$=(0.2)$ & -5.07 & -4.47 & -4.20 \\
\hline$=(0.3)$ & -5.15 & -4.45 & -4.18 \\
\hline$=(0.4)$ & -5.05 & -4.50 & -4.18 \\
\hline$=(0.5)$ & -5.11 & -4.51 & -4.17 \\
\hline
\end{tabular}

\subsection{Unit root test with two structural breaks}

The results of the Lee and Strazicich unit root test with two endogenous structural breaks are presented in Table 5. The two-break test rejects the unit root in favour of the two-break stationary alternative for a total of 6 of the 10 macroeconomic series considered. With the Lee-Strazicich (LM) test, we reject the unit root null in favour of the stationarity with two structural breaks alternative at $1 \%$ for government final expenditure and gross domestic products, at 5\% for crude oil price and at $10 \%$ for exports of goods and services, exchange rate and money and quasi money (M2). 
Table 5: Two endogenous structural breaks Lee-Strazicich unit root test

\begin{tabular}{|c|c|c|c|c|c|c|}
\hline Variables & $\widehat{\boldsymbol{k}}$ & $\begin{array}{l}\text { Break } \\
\text { date } 1\end{array}$ & $\begin{array}{l}\text { Break } \\
\text { date } 2\end{array}$ & $\begin{array}{c}\text { Test } \\
\text { statistic }\end{array}$ & $\begin{array}{c}\text { Break } \\
\text { fractions } \\
(\lambda)\end{array}$ & Inference \\
\hline GOFE & 4 & 2003:03 & 2009:04 & $-9.1702 * * *$ & $0.7,0.8$ & $\begin{array}{c}\text { Two breaks } \\
\text { stationary }\end{array}$ \\
\hline LGDP & 3 & 2007:03 & 2010:04 & $-8.2632 * * *$ & $0.8,0.9$ & $\begin{array}{c}\text { Two breaks } \\
\text { stationary }\end{array}$ \\
\hline LEXPO & 4 & 1988:01 & 2008:03 & $-5.4988 *$ & $0.2,0.8$ & $\begin{array}{c}\text { Two breaks } \\
\text { stationary }\end{array}$ \\
\hline LIMPO & 0 & 1986:04 & 2006:04 & -5.1668 & $0.2,0.8$ & Unit root \\
\hline LASHI & 3 & 1994:04 & 2003:04 & -4.4992 & $0.3,0.6$ & Unit Root \\
\hline LWAGE & 0 & 1989:04 & 2005:04 & -4.7804 & $0.3,0.8$ & Unit Root \\
\hline CPI & 4 & 1999:01 & 2009:03 & -4.4290 & $0.2,0.7$ & Unit Root \\
\hline $\mathrm{EXCH}$ & 4 & 1998:03 & $2002: 03$ & $-5.5221 *$ & $0.5,0.6$ & $\begin{array}{c}\text { Two breaks } \\
\text { stationary }\end{array}$ \\
\hline CROP & 1 & 2002:02 & 2011:04 & $-6.2850 * *$ & $0.6,0.9$ & $\begin{array}{l}\text { Two breaks } \\
\text { stationary }\end{array}$ \\
\hline M2 & 4 & 1997:04 & 2004:01 & $-5.3801 *$ & $0.5,0.7$ & $\begin{array}{c}\text { Two breaks } \\
\text { stationary }\end{array}$ \\
\hline
\end{tabular}

$* * *, * *$ and $*$ denote statistical significance at $1 \%, 5 \%$ and $10 \%$ respectively.

Note: $\hat{\mathrm{k}}$ is the AIC lag term is used to select the optimal lag, to make the residuals white noise. $\lambda$ denotes the estimated break points.

Table 6: Lee and Strazicich Critical Values for Two-Structural Break Test

\begin{tabular}{|c|c|c|c|}
\hline Break points & \multicolumn{3}{|c|}{ Critical values } \\
\hline$=\left(\mathrm{T}_{\mathrm{B} 1} / \mathrm{T}, \mathrm{T}_{\mathrm{B} 2} / \mathrm{T}\right)$ & $1 \%$ & $5 \%$ & $10 \%$ \\
\hline$=(0.2,0.4)$ & -6.16 & -5.59 & -5.27 \\
\hline$=(0.2,0.6)$ & -6.41 & -5.74 & -5.32 \\
\hline$=(0.2,0.8)$ & -6.33 & -5.71 & -5.33 \\
\hline$=(0.4,0.6)$ & -6.45 & -5.67 & -5.31 \\
\hline$=(0.4,0.8)$ & -6.42 & -5.65 & -5.32 \\
\hline$=(0.6,0.8)$ & -6.32 & -5.73 & -5.32 \\
\hline
\end{tabular}

Source: Lee and Strazicich (2003) 
In addition, the two endogenous structural breaks test rejects the unit root hypothesis more than one endogenous structural break test; this is possibly due to under specification of the number of structural breaks. This is consistent with Ohara (1999) findings. Ohara (1999) proved that tests with fewer than the true number of structural breaks fail, incorrectly, to reject the unit root null even asymptotically. Howbeit, the minimum LM two-break test and the one-break test considered in our study could not reject the unit root null hypotheses of import of goods and services, all share index, compensation of employees (Wages) and inflation rate.

\subsection{Conclusion and Recommendations}

This paper provides a comprehensive examination of the unit root hypothesis and structural breaks of 10 Nigerian macroeconomic time series utilizing quarterly data from 1981 - 2015. Utilizing the ADF test, the study finds very weak evidence against the unit root null hypothesis as the unit root null hypothesis could only be rejected for one of the ten series. However, on employing the end ogenous onebreak and two-break tests, it was found that evidence against the unit root hypothesis increased. In fact, $60 \%$ of the series considered in this study, rejected the unit root hypothesis in favour of the one or two breaks stationary alternative. Some of the estimated break dates were quite significant because they corresponded to important economic events such as the Nigeria transition to democracy in 1999, the stock market crash in 2002 and the global financial crises in 2008. The findings that six of the macroeconomic series are stationary with one or two breaks is quite important for econometric modeling of the macroeconomic variables because if a variable is stationary with structural break(s), but erroneously regarded as a unit root series, misleading inferences would inevitably result. Since most of the macroeconomic series considered in the study appear to be stationary with structural break(s), this implies that the effects of shocks to these series will be transitory and thus eliminated as time elapses.

This empirical analysis does not address the possibility of a model with three or more breaks. In addition, there has been increased interest on how structural breaks affect fractional intergregration and long memory, see for examples, Perron and $\mathrm{Qu}$ (2010) and Varneskov and Perron (2011). Moreover, the detection of structural break using the state space model via the Kalman filter is also a recent focus in the literature. We are aware of these shortcomings and new direction and the hope to report empirical analytical results on these issues in subsequent research. 


\section{References}

1. Adaramola, A.O. (2012). Oil Price Shocks and Stock Market Behaviour. J. Economics, 3(1):19-24.

2. Banerjee, A., Lumsdaine, R. and Stock, j (1992). Recursive and Sequential Tests of the Unit Root and Trend Break Hypotheses: Theory and International Evidence. Journal of Business and Economic Statistics, 10:271-287.

3. Bjornland, H.C. (2010). Structural Breaks and Stochastic Trends in Macroeconomic Variables in Norway. Applied Economics Letters, 6:133-138.

4. Chaudhuri, K. and Wu, Y. (2003). Random Walk versus Breaking Trend in Stock Prices: Evidence from Emerging Markets. Journal of Banking and Finance, 27:575-592.

5. Christiano, L (1992). Searching for a Break in GNP. Journal of Business and Economic statistics, 10:237-250.

6. Dickey, D.A. and Fuller, W.A. (1979). Distribution of the Estimators for Autoregressive Time Series with a Unit Root. Journal of the American Statistical Association, 74:427-43.

7. Dickey, D.A. and Fuller, W.A. (1981). Likelihood Ratio Statistics for Autoregressive Time Series with a Unit Root. Econometrica: Journal of the Econometric Society, 75:1057-1072.

8. Folawewo, A.O (2012). Is there Hysteresis in Nigerian Unemployment Rate? : An Application of the Unit Root Test with Structural Breaks. The Nigerian Journal of Economic and Social Studies, 54(3):313-328.

9. Hall, A.D (1994). Testing for a Unit Root in Time Series with Pretest DataBased Model Selection. Journal of Business \& Economic Statistics, 12:461470 .

10. Lee, J. and Strazicich, M.C (2003). Minimum Lagrange Multiplier Unit Root Test with Two Structural Breaks. Review of Economics and Statistics, 85(4):1082-1089.

11. Lee, J. and Strazicich, M.C (2013). Minimum Lagrange Multiplier Unit Root Test with One Structural Break. Economics Bulletin Vol., 33(4):2483-2892.

12. Luísa, A., Abras, G., Braulio, L.B. and Rodrigo, M.S (2006). Breaking Trend, Lagrange Multiplier Test Statistic and the Presence of a Unit Root in the Brazilian Gross Domestic Product.Applied Economics Letters, 11(6):361-364.

13. Lumsdaine, R.L. and Papell, D.H. (1997). Multiple Trend Breaks and the UnitRoot Hypothesis. Review of Economics and Statistics, 79:212-218. 
14. Narayan, P.K. and Smyth, R. (2005). Are OECD Stock Prices Characterized By a Random Walk: Evidence from Sequential Trend Break and Panel Data Models?Applied Financial Economics, 15:547-556.

15. Nelson, C.R. and Plosser, C.I. (1982). Trends and Random Walks in Macroeconomic Time Series: Some Evidence and Implications. Journal of Monetary Economics, 10:139-162.

16. Nunes, L., Newbold, P. and Kuan, C. (1997). Testing for Unit Roots with Breaks: Evidence On The Great Crash and the Unit Root Hypothesis Reconsidered. Oxford Bulletin of Economics and Statistics, 59:435-448.

17. Ohara, I.H (1999). A Unit Root Test with Multiple Trend Breaks: A Theory and an Application to US and Japanese Macroeconomic Time Series. The Japanese Economic Review, 50(3):266-290.

18. Osamwonyi, I.O. and Osagie, E.I.E. (2012). The Relationship between Macroeconomic Variables and Stock Market Index in Nigeria. J Economics, 3(1):55-63.

19. Perron, P. (1989). The Great Crash, the Oil Price Shock, and the Unit Root Hypothesis.Econometrica, 57:1361.

20. Perron, P., and Qu, E. (2010). Long Memory and Level Shifts in the Volatility of Stock Market Indices. Journal of Business and Economic Statistics, 28:275290.

21. Tamunonimim A.N.A (2013). Unraveling the Uncertainty of the Niger Delta Crisis Through Taxation. Asian Economic and Financial Review, 3(2):186-195.

22. Tatoglu, F.Y. (2009). Analyzing the Stationarity of Real Effective Exchange Rates Using Panel Unit Root Tests ith Structural Breaks. Dogus Universitesi Dergisi, 10(2):310-323.

23. Varneskov, R. T., and Perron, P. (2011). Combining Long Memory and Level Shifts in Modeling and Forecasting the Volatility Of Asset Returns. Creates Research Paper Aarhus University, 2011:26.

24. Vougas, D.V (2003). Reconsidering LM Unit Root Testing. Journal of Applied Statistics, 30(7):727-741.

25. Waheed, M., Alam, T. and Ghauri, S.P. (2006). Structural Breaks and Unit Root: Evidence from Pakistani Macroeconomic Time Series. Available online at: https://mpra.ub.uni-muenchen.de/1797/

26. Zivot, E. and Andrews, D.W.K. (1992). Further Evidence on the Great Crash, the Oil-Price Shock and the Unit-Root Hypothesis. Journal of Business and Economic Statistics, 10(3):251-270. 